\title{
Razões em três tempos: uma análise compa- rativa entre três versões do texto "Razões para uma nova arquitetura" de Lucio Costa
}

\author{
Reasons in three times: a comparative analysis between three versions of \\ Reasons for a new architecture
}

Christine de Pinho Meirelles*, Ana M. G. Albano Amora**

*Mestranda pelo Programa de Pós-Graduação em Arquitetura Universidade Federal do Rio de Janeiro (PROARQ/UFRJ), Arquiteta e Urbanista pela Faculdade de Arquitetura e Urbanismo da Universidade Federal do Rio de Janeiro (FAU-UFRJ).

ORCID: $\quad 0000-0002-4706-$ 2597
**Doutora pelo Instituto de Pesquisa e Planejamento Urbano e Regional da Universidade Federal do Rio de Janeiro (IPPUR/UFRJ). Professora Programa de PósGraduação em Arquitetura Universidade Federal do Rio de Janeiro (PROARQ UFRJ). Bolsistade Produtividade CNPQ. Coordenadora Dinter do Programa de PósGraduação em Arquitetura da Universidade Federal da Fronteira Sul (PROARQ/ UFFS).

ORCID: 0000-0001-86139502

\section{Resumo}

Nossa proposta neste artigo é apresentar e comparar de forma critica as alterações sofridas desde a sua primeira versão do 'Razões para uma nova arquitetura', texto que traz pela primeira vez os argumentos nos quais Lucio Costa se baseia para sustentar sua posição em favor de uma nova arquitetura, em duas subsequentes edições. A primeira versão, de 1934, foi publicada na Revista da Diretoria de Engenharia da prefeitura do Distrito Federal, em janeiro de 1936, a intermediária, de 1962, foi publicada em 'Lúcio Costa: Sobre a Arquitetura', uma coletânea de textos organizada por Alberto Xavier. Já a última, publicada em 1995, encontra-se no livro 'Lucio Costa. Registro de uma vivência'.

Palavras-chave: Lucio Costa. Arquitetura moderna. Tradição.

\section{Abstract}

Our proposal in this article is to present and critically compare the changes suffered since first version of 'Reasons for a new architecture', a text that brings for the first time the arguments on which Lucio Costa is based to support his position in favor of a new architecture, in two subsequent editions. The first version, from 1934, was published in the Magazine of the Directorate of Engineering of the prefecture of the Federal District, in January 1936, the intermediate one, from 1962, was published in 'Lúcio Costa: Sobre a Arquitetura', a collection of texts organized by Alberto Xavier. The last, published in 1995, is found in the book 'Lucio Costa. Registro de uma vivência'.

Keywords: Lucio Costa. Modern architecture. Tradition.

\section{(c) (7) \&}

Recebido: 05/05/2020

Aceito: $30 / 06 / 2020$

https://doi.org/10.37916/arq.urb.v28i.432 
1. O foco da análise está nas transformações do texto em si, no conteúdo das ideias do autor, e não na linguagem utilizada. Apesar de a língua portuguesa ter sofrido transformações desde a publicação da primeira versão do texto em 1936, e essas transformações serem visíveis na escrita em cada edição, as palavras cuja ortografia foi corrigida em fun-

ção desse contexto não serão consideradas.

2. Será utilizado o dicionário Houaiss, do Instituto Antônio Houaiss de Lexicografia.

3. Na descrição do texto, escrita por Lucio Costa, em Registro de uma vivência aparece a data de 1934 .

\section{Introdução}

texto "Razões da nova arquitetura" de Lucio Costa traz pela primeira vez os argumentos nos quais este $o$ arquiteto se baseia para sustentar sua posição, e definir o veio central da produção arquitetônica moderna no Brasil, no encontro de duas posições aparentemente opostas: o passado e a tradição, e o futuro idealizado da modernidade (NOBRE, 2002).

Este texto foi reeditado e publicado algumas vezes, em épocas distintas. Assim, a proposta neste artigo é apresentar e comparar de forma crítica as alterações sofridas na passagem de tempo entre três versões com seus conjuntos de "razões", que nos parecem ter como objetivo enaltecer a chamada pelo próprio arquiteto de nova arquitetura, e que são reveladas ou omitidas nesse transcurso.

A partir de um esforço analítico empreendido para se entender as diferenças do discurso do autor, serão consideradas três dessas versões, com cerca de 20 anos de diferença entre as publicações. Vale esclarecer que elas serão apresentadas depois dos veículos aos quais elas estão vinculadas, revistas ou livros, e, então, cada modificação no texto será destacada e terá o significado analisado com base na definição do dicionário ${ }^{2}$, e na bibliografia referente ao assunto.

A primeira versão considerada, que chamaremos de "versão 1", segundo o próprio autor foi escrita em $1934^{3}$, (COSTA, 1995, p. 108) e publicada na Revista da Diretoria de Engenharia da Prefeitura do Distrito Federal em 1936. A intermediária, que chamaremos de "versão 2", foi publicada em 1962 em Lucio Costa: sobre a Arquitetura, uma coletânea de textos do arquiteto organizada por Alberto Xavier. Neste caso, utilizamos a edição do ano de publicação. Já a última, que chamaremos de "versão 3" foi publicada em 1995 no livro Registro de uma vivência, e a edição foi também a do ano da publicação.

$\mathrm{Na}$ "versão 2", o organizador Alberto Xavier destaca, por meio de comentários nas laterais das páginas, as temáticas que o texto aborda, cujo objetivo seria facilitar a separação de trechos do texto para estudo, que funcionariam como subtítulos (XAVIER, 1962). Com o objetivo de também melhor organizar 
4. Segundo Mario de Andrade sobre a exposição Brazil Builds no MoMa (1943), a primeira "escola" de arquitetura moderna foi criada no Rio de Janeiro, tendo Lucio Costa à frente. (ANDRADE, 2003).

5. A ordem em que os textos de Costa aparecem no livro é cronológica e a data indicada é preferencialmente a de quando foram escritos. Apenas quando essa informação não esteve disponível para Xavier que é indicada, em vez disso, a data em que foram publicados. Dessa forma, o primeiro texto do livro é "O Aleijadinho e a arquitetura tradicional", de 1929, e logo em seguida vem "Razões da nova arquitetura", indicando 1930 como a data em que foi escri-

6. A edição do livro Registro de uma vivência não obedece necessariamente a uma ordem cronológica dos textos, cartas ou desenhos. Entretanto, "Razões da nova arquitetura" aparece na página 108 depois de projetos e acontecimentos relatados que, de fato, são anteriores a sua primeira publicação. Exemplos disso é a viagem à Diamantina (1924), a parceria com Gregori Warchavchik (1931), o projeto na Vila da Gamboa (1932) e o projeto para a vila de Monlevade (1934).

7. De acordo com nota do Centro de Pesquisa e Docu- mentação de História Conemporânea do Brasil, a Universidade do Distrito Federal
(UDF), criada em abril de (UDF), criada em abril de 1935 pelo Decreto Municipal
$n^{\circ} 5.513$, tendo Anísio Teixeira na direção do Departamento de Educação, pre位 telectuais do tudo, após uma grave crise provocada pela revolta comunista de 1935, envol-vendo a demissão de Anísio Teixeira, em 1937 a UDF forma sua primeira turma. Aperar Apesar disso, a UDF conrariava o projeto de Gustavo Capanema de fortalecimento da Universidade do Brasil, e, depois, a instauração do Estado Novo em novembro de 1937 levou a sua eliminação. dra ados à Faculdade Nacional de Filosofia da Universidade do Brasil (CENTRO DE PESQUISA..., [2019]).

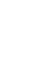

a análise textual nesta nossa leitura, respeitamos e utilizamos essa subdivisão em temas.

Dessa forma, primeiro as citadas publicações, seus respectivos veículos e contexto serão comentados Depois, iniciaremos a análise do texto, na qual as referidas versões foram lidas e comparadas frase a frase, com as alterações grifadas e apresentadas neste artigo para serem comentadas, organizadas segundo os temas indicados por Alberto Xavier, como já dito, com a utilização do dicionário Houaiss, do Instituto Antônio Houaiss de Lexicografia, e em dialogo com autores como: Ana Albano Amora, Ana Luiza Nobre, Edgar Graeff, e Otávio Leonídio Ribeiro, e . Em seguida serão feitas as considerações finais levando em conta os resultados recolhidos anteriormente.

\section{As Publicações}

O veículo em que se publicou a "versão 1", a $R e$ vista da Diretoria de Engenharia da prefeitura do Distrito Federal, foi criada em janeiro de 1932, e, de acordo com Ana Albano Amora (2009), apesar de ter como objetivo discutir e apresentar propos tas para as cidades, era, na sua primeira etapa, claramente vinculada ao pensamento arquitetônico moderno e sua difusão sobretudo, divulgava ideias e projetos dos arquitetos da "escola carioca".

Lúcio Costa: sobre a Arquitetura, em que se encontra a "versão 2", é uma coletânea de textos que incluiu cartas, entrevistas, manifestações e pronunciamentos de Lucio Costa, organizado por Alberto Xavier. Tal publicação, segundo nota introdutória de Edgar Graeff, foi editada sob o patrocínio da Faculdade de Arquitetura da Universidade Federal do Rio Grande do Sul, UFRGS. Isto se deu a partir de reivindicações dos estudantes, que consideravam incompleta uma publicação anterior, também de iniciativa da faculdade, datada de 1954, sobre parte da obra do arquiteto. Graeff (GRAEFF, 1962) relata que, durante a organização do livro, Alberto Xavier coletou todo o material silenciosamente, pois temia possíveis reações de Costa, que poderiam paralisar seu trabalho. Entretanto, essa atitude também dificultou a coleta de dados, o que acarretou o uso de poucas fontes de pesquisa. ${ }^{5}$

Já Registro de uma vivência, publicação na qual se encontra a "versão 3", é uma compilação de textos, cartas, desenhos, fotografias e projetos de Lucio Costa, cuja seleção foi do próprio arquiteto e a edição da sua filha Maria Elisa Costa. No livro, o texto aparece datado de $1934^{6}$ e é descrito como parte de um programa para um curso de pós-graduação do Instituto de Artes na antiga Universidade do Distrito Federal, criada por Anísio Teixeira. ${ }^{7}$ Tal afirmação é contestada por Otávio Leonídio Ribeiro, que considera os objetivos do texto incertos, tendo em vista, primeiro, a extensão do texto e, depois, a falta de qualquer menção a alguma disciplina ou atividade didática (RIBEIRO, 2007). 
8. A crucialidade do momento termo só é utilizado quando indica que as intenções do ar- se refere ao contexto, aos arquiteto fossem além do ambi- quitetos ou a outros campos, como a pintura, por exemplo. ente restrito das salas de aula 12."Evolução", mesmo sendo e do debate pedagógico. Pos- um termo considerado datado sivelmente, estava marcando por expressar uma visão de um ponto importante na "guer- Darwinismo social, é usada ra santa" em que eram decidi- por Ribeiro fazendo referência dos os rumos da produc̃ão ao texto original de Lucio quitetônica brasileira (LEONÍDIO, 2007, p. 145).

9. "Guerras culturais" eram estabelecidas entre diferentes posições frente ao que deveria representar a nação e a nacionalidade brasileira (WILLIAMS, 2001 apud AMORA, 2006, p. 70).

10. O post-scriptum, de 1991, é posterior a primeira publicação de "Razões da nova arquitetura" em 1936, mas anterior a publicação do livro $\mathrm{Re}$ gistro de uma vivência, em 1995.

11. Na versão publicada em Registro de uma vivência, Costa acrescenta um postscriptum, , no qual diferencia moderno e "modernista" e explica que a arquitetura moderna de fato seria aquela que passou por um processo, como no Brasil, em que a busca pelas raízes e tradições, combinada à verdadeira abertura para o mundo moderno, torna essa arquitetura legítima (COSTA, 1995, p. 116). Contudo, em todo o texto, Lucio chama tal arquitetura de nova e, algumas vezes, contemporânea, não moderna. O uso do

usjt • arq.urb • número 28 | maio - agosto de 2020
Nesta mesma descrição sobre o contexto da produção do texto analisado em Registro de uma vivência há um comentário sobre o que Costa chama de uma "guerra santa" profissional, que parece apontar em direção às reais intenções do referido texto, corroborando com a contestação de Ribeiro sobre este ser realmente um programa de curso ou ir além disso. Diz Costa: "Transcrevo esse longo texto como um documento de época que revela o clima de 'guerra santa' profissional"8 (COSTA, 1995, p. 108).

Ainda sobre este trecho na descrição do texto em Registro de uma vivência, quando Lucio Costa escolhe palavras como "transcrevo" ou "como documento de época", isso pode soar controverso. Afinal, o texto sofreu diversas mudanças desde o original, algumas dessas ainda com faces de eufemismo justamente sobre a posição do arquiteto nesse contexto de luta por representação acerca da modernidade na arquitetura (LISSOVSKY, 1996 apud AMORA, 2006). Ainda mais, porque segundo Amora (2006, p. 2), Lucio Costa é presença significativa na formação do ideário moderno em um momento no qual eram travadas "guerras culturais" 9 entre tradição e modernidade.

Essa versão traz ainda um post-scriptum ${ }^{10}$ datado de 1991, em que se alerta sobre designações inadequadas, como sobre as diferenças entre moderno e "modernista". ${ }^{11}$ Por outro lado, traz um elogio à arquitetura moderna no Brasil, que, segundo
Costa, teria de fato se aberto para o mundo moderno, ao mesmo tempo em que mergulhara em busca de suas raízes como nação.

\section{Análise do texto}

Em "Razões da nova arquitetura" Lucio Costa parte da premissa inicial de que períodos de transição são imprecisos, de difícil adaptação ao novo e aceitação às mudanças. Trazendo para a realidade brasileira, ele explica que o problema principal de que trata o texto é o descompasso entre as possibilidades da nova técnica e da sociedade se adequar a ela, com as necessidades próprias do seu tempo, e o anacronismo da produção arquitetônica vigente.

Conforme Leonídio Ribeiro (op.cit), esse texto, constituinte da base da teoria de Costa, pode ser dividido a partir de dois pontos fundamentais. O primeiro, pressuposto básico, é que a evolução ${ }^{12}$ e as transformações pelas quais a arquitetura passara aconteceram de maneira cíclica e sistêmica, em que períodos de equilíbrio foram sucedidos por períodos de desequilíbrio e de crise, e assim por diante - e o momento do qual Costa falava seria um desses períodos de transição. O segundo é que a arquitetura de um determinado período deveria estar em conformidade com a sociedade a que faz parte, e que o acordo entre arquitetura e sociedade deveria se pautar pela técnica, no caso, a nova técnica. Dessa forma, a questão central do texto, a crise da arquitetura contemporânea, advinha de um descompasso 
13. "Razões da nova arquitetura" é datado de 1934 por Costa (1995), mas considerando a data de publicação, 1936.

14. Cabe notar que esse trecho específico do texto aparece de forma idêntica em todas as versões analisadas.

15. Nada se altera nessas

duas versões. historicamente localizado entre arquitetura e sociedade, no qual a técnica já estava mais avançada que a arquitetura vigente (RIBEIRO, 2007).

Outro ponto a se tratar é que podemos ver que o texto original foi difundido em uma importante fase de transição também para o próprio arquiteto ${ }^{13}$. (BRITO, 2014) Fato representativo disso é que já em 1930 Costa propõe dois projetos diversos para a casa E. G. Fontes. O primeiro foi chamado em Registro de uma vivência de "última manifestação de sentido eclético-acadêmico" e o segundo, "primeira proposição de sentido contemporâneo" com o uso de pilotis (COSTA, 1995 p. 58-60).

$\mathrm{Na}$ análise do texto, partiu-se da escolha de Alberto Xavier (XAVIER, 1962) de subtítulos e comentários, como já dito, destacando-se os principais pontos do texto de Lucio Costa em cada trecho. Assim, seguimos a estrutura deste, começando pela premissa, ponto de partida da argumentação, intitulada como "Um período de transição; alcance das transformações" (XAVIER, 1962, p. 17), em que Costa diz: "(...) Nessa fase de adaptação a luz tonteia e cega os contemporâneos - há tumulto, incompreensão: demolição sumária de tudo que precedeu; negação intransigente do pouco que vai surgindo". ${ }^{14} \mathrm{O}$ arquiteto destaca o perfil impreciso de determinados períodos e explica a reação dos contemporâneos sobre novidades eminentes. Considera que quando a coesão de determinado equilíbrio se rompe, e um novo deve ser buscado, aqueles que observam esse processo têm dificuldades em enxergar a mudança e de se adaptar a ela.

Logo no trecho seguinte em destaque, "Incompreensões e desajuste entre a nova arquitetura e as condições da atual sociedade" (XAVIER,1962, p. 17), em que Lucio Costa introduz o problema principal do texto, ou seja, o descompasso entre as possibilidades da nova técnica e da sociedade, já se revelam mudanças no texto. A palavra "imbecilidade" usada nas "versões 1 e 2 "15 é substituída pela palavra "incompreensão" na "versão 3", referindo-se ao que ele chama de "pseudoarquitetura", que na sua visão apenas documenta o desajuste entre a técnica e os novos interesses da sociedade que a acompanha (COSTA, 1995, p. 108).

Segundo a definição do dicionário, a palavra "imbecilidade" significa: "inteligência curta, ou pouco juízo; idiota, tolo"; enquanto que a palavra "incompreensão" significa: "que não foi suficientemente entendido, reconhecido, valorizado" (INSTITUTO ANTONIO..., 2015).

O significado da primeira palavra relaciona-se com o ato de errar de forma ativa, demonstrando, em uma atitude, aquilo que já se encontrava decidido. Já a segunda palavra transmite passividade maior, um problema de leitura sem a intenção de cometer erros. Assim, observamos que o texto da "versão 3" apresenta-se de forma mais branda, um eufemis- 
16. Os grifos mostram o trecho da "versão 1" e da "Versão 2" excluído da "versão 3".

17. Palavra existente apenas na "versão 3" de 1995

usjt • arq.urb • número $28 \mid$ maio - agosto de 2020 mo, talvez, para suavizar a forma enfática dos primeiros tempos de "guerra" pelo novo, depois não mais necessária.

No ponto seguinte, a "Revolução: receptividade e liberdade do artista" (XAVIER, 1962, p. 19), Costa discorre sobre a falta de uma sincronia evolutiva entre arquitetura e o ambiente social e tecnológico e fala que, apesar de na sua visão já ser possível uma nova arquitetura adequada a seu tempo, isso não se trata de um problema isolado desse campo do conhecimento, abrindo a discussão aos outros campos da arte.

Mais adiante, Costa conclui que, se há possibilidade de maior abertura para novidades e experimentações, tendo em vista a instabilidade causada pela sua premissa de um período de transição, logo, os artistas poderiam ser o início da solução para o problema do descompasso, porque a revolução tenderia a começar por eles, já que captariam com facilidade o momento e o traduziriam em obras de arte.

Indo além, nesse desencadear de argumentos lógicos, Lucio Costa pensa a respeito da revolução que então teria início por meio da ação dos artistas. Ao analisar a situação, o autor coloca em dúvida essa premissa como solução e diz que talvez isso não configure uma resposta final, mas apenas como uma forma de romper os limites iniciais, aos quais compara metaforicamente a uma encosta, pela dificuldade de subida. Sendo assim, a revolução, para o autor, seria um meio para atingir o resultado final, e um determinado estado de equilíbrio. Nesse ponto do texto, encontramos divergências entre a edição de 1995, "versão 3", em relação às anteriores, nas quais nada é alterado.

"Versão 1" e "Versão 2": (...) fértil, exatamente como a escada que nos interessa, quando cansados, em vista de alcançar o andar, onde estão o quarto e a cama. ${ }^{16}$ Conquanto o simples fato de subi-la dois a dois já possa constituir, àqueles espíritos irrequietos e turbulentos que avocam a si a pitoresca condição de "revolucionários de nascença" , o maior - quiçá mesmo o único prazer, a nós outros, espíritos normais, aos quais o rumoroso sabor da aventura não satisfaz, interessa exclusivamente como meio de alcançar outro equilíbrio, conforme com a nova realidade que, inelutável se impõe (COSTA, 1936, s/p., grifos nossos).

"Versão 3": (...) fértil. Conquanto esse fato de vencê-la em luta possa constituir, àqueles espíritos irrequietos e turbulentos que avocam a si a pitoresca condição de "revolucionários de nascença", o maior - quiçá mesmo o único prazer, a nós outros, espíritos normais, aos quais o rumoroso sabor da aventura não satisfaz, interessa exclusivamente como meio penoso ${ }^{17}$ de alcançar outro equilíbrio, conforme com a nova realidade que, inelutável se impõe (COSTA, 1995, p. 109, grifos nossos).

A frase retirada enfatiza a metáfora da encosta, em que existem níveis em alturas diferentes a serem 
18. Ver nota 12

19. Na versão de 1936 "versão 1' está escrito "totalmente" e não "tolamente" como na de 1962, mas não tivemos acesso a erratas da revista na qual o texto foi publicado em 1936 e, sim, à errata de 1962, em que não constavam correções. Além disso, entre as duas versões há pouca ou nenhuma edição em relação ao sentido, apenas a escrita correta de cada época. Essa alteração não foi considerada.

20. Palavra incluída na "versão 2" substituindo a palavra "totalmente" e retirada na "versão" 3.

usjt • arq.urb • número 28 | maio - agosto de 2020 superados. O meio de vencer o desnível, seria a escada, por ser esta um instrumento que exigiria gasto energético. Assim, a ênfase presente na frase retirada é substituída apenas pelo adjetivo "penoso".

Outra questão seria a da "Comunhão e desintegração das artes" (XAVIER, 1962, p. 20), pois, para Lucio Costa, se a revolução é apenas um meio de se chegar ao equilíbrio, vencendo a barreira inicial, então a fase seguinte seria subir ao próximo nível. Esse nível, segundo Costa, seria um patamar em que a nova ideia já estaria difundida e poderia seguir seu desenvolvimento. Nele, em seu ponto de vista, as artes caminhariam juntas, integradas. Entretanto, depois que a ideia já estivesse desenvolvida, as artes se afastariam, ou como em suas palavras, desintegrariam novamente em suas especificidades, constituindo um novo movimento cíclico.

Para falar desse movimento que implicaria em equilíbrio, seguido de desacordo, comunhão e desintegração, Lucio Costa usa a metáfora apresentada acima, referente ao ato de subir, remetendose ao decorrer histórico baseado na produção manual até o tempo em que o texto foi escrito como uma penosa evolução ${ }^{18}$. Dessa forma, ele sugere que o advento de um tipo de elevador tornaria a subida mais contínua e sem os, chamados por ele, "arrancos da escada" (COSTA, 1995, p. 110).
Nesse trecho da edição de 1995, "versão 3", novamente encontramos uma palavra suprimida amenizando o teor um tanto agressivo dos textos anteriores. ${ }^{19}$ Diz Costa:

"Versão 2": (...) a nova ideia já então suficientemente difundida, é o próprio ar que se respira, e, no gozo consciente da nova alegria conquistada, uníssona, começa em côro, a verdadeira ascensão: movimento legítimo, de dentro pra fora e não o inverso, como tolamente,,$^{20}$ se receia (COSTA, 1936 apud COSTA, 1962, p. 20).

Em seguida, um parágrafo inteiro, presente na "versão 1" e na "versão 2", é retirado da versão de 1995, porque acreditamos ficaria sem sentido com a retirada da frase anterior em que Costa utiliza a comparação entre a escada e o elevador como metáforas da subida em uma encosta. O parágrafo é o seguinte:

"Versão 1" e "Versão 2": Assim tem sido e ainda será enquanto não atingirmos, se é que atingiremos, a um grão de evolução que nos permita ascensão normal e contínua, substituindo-se (para desespero dos bons quixotes) o "elevador" aos penosos arrancos da "escada" (COSTA, 1936).

Em relação ao "Trabalho manual e advento da máquina" (XAVIER, 1962, p. 21), o autor vê um problema que é a desagregação presente no movimento de assimilação das novas ideias. Ele percebe que haveria primeiramente descompasso entre a arquitetura e as forças da modernidade para, depois, se 
21. Considerando a primeira data, 1936.

22. Palavra retirada. alcançar um novo nível em que as primeiras barreiras seriam vencidas, com a companhia das outras artes. Entretanto, novamente o desequilíbrio se instauraria, e a integração entre as artes conquistada tenderia à desagregação. $\mathrm{O}$ arquiteto busca o porquê dessa desagregação, sem tirar a arquitetura e suas especificidades do foco principal. E em busca dessa resposta, analisa o esforço da sociedade em se adaptar ao que chama de "novas circunstâncias e condições de vida" e considera o fato de que, até aquele momento, ${ }^{21}$ essas circunstâncias e condições se manifestavam apenas por meio de trabalhos manuais, o que garantiria ter sido entendido como uma condição permanente pela tradição, um dogma. Sendo assim, essa limitação de até que ponto os avanços da arquitetura dependeriam da lógica dos trabalhos manuais teria duas faces, uma técnica e outra ideológica em função dos meios social e físico (COSTA, 1995, p. 110).

Contudo, Costa acreditava que a arquitetura não se prenderia necessariamente ao passado, e o descobrir do novo não precisava se dar como antes. $O$ trabalho manual era algo importante nos séculos anteriores, mas o surgimento de novas técnicas e a produção industrial, que alterariam essa dinâmica, deveriam ser levadas em consideração numa nova conjuntura. Assim, os argumentos da tradição como dogma se baseariam em premissas ultrapassadas.
No parágrafo do texto, no qual Costa explica essa alteração, algumas palavras foram trocadas, mas há poucas mudanças realmente relevantes para o sentido do texto. Na última linha, quando conclui que a transformação da técnica deixaria sem sentido o pensamento sobre os limites do desenvolvimento da arquitetura, antes com baseada no trabalho manual e exemplificado no texto a partir técnica do condicionamento do ar, observamos que na "versão 3" de 1995, o trecho "(...) anulará por completo" (COSTA, 1936) é substituído por "poderá anular por completo". Esta adição que leva uma certeza anterior à uma categoria de hipótese (COSTA, 1995, p. 110).

Em seguida, observamos na Versão 3 a retirada da palavra "manual" do texto abaixo. Com isso a sentença não restringe mais a possibilidade daquele que trabalha com materiais ou processos industrializados de ser um artífice hábil, como a frase presente nas versões anteriores. Ainda que as matériasprimas utilizadas sejam provenientes de processos industriais, elas podem ser articuladas de maneira que possam ser encaixadas aos processos de produção de um artífice, mas esse conceito teria maior flexibilidade.

"Versão 1" e "Versão 2": As corporações e famílias transmitiam, de pai a filho, os segredos e minúcias da técnica, sempre circunscrita às possibilidades do material empregado e à habilidade manual $^{22}$ do artífice, por mais alado que possa ter sido o engenho (COSTa, 1936, s/p., grifo nosso). 
23. Palavra retirada.

24. Como dito anteriormente,

a tradição, no sentido de hábi-

to, dogma, nesse caso, ligava-

se à produção manual.
E, então, na sequência, o trecho sobre a máquina e a grande indústria presente na primeira versão ("versão 1"), e inalterado na segunda ("versão 2"), demonstra uma urgência relacionada à nova conjuntura, como que uma imposição, que não está presente no contexto da "versão 3", de 1995, na qual a palavra "impondo" foi retirada.

"Versão 1" e "Versão 2": A máquina, com a grande indústria, veio, porém, perturbar a cadência desse ritmo imemorial, tornando a princípio possível, já agora impondo, ${ }^{23} \mathrm{sem}$ rodeios o alargamento do círculo fictício em que, como bons perus, cheios de dignidade, ainda hoje nos julgamos emprisionados (COSTA, 1936, s/p., grifo nosso).

No tema destacado por Alberto Xavier (1962, p. 23) como "A lição dos meios de transporte; arquitetura e individualismo", o objetivo é solucionar o descompasso entre a arquitetura vigente e as possiblidades de um novo contexto em relação aos avanços tecnológicos. Nesse momento, Lucio Costa utiliza um exemplo de um outro campo para isso, como metáfora pouco original que revela o viés Corbusiano. Como enuncia Otávio Leonídio Ribeiro, é possível ver a influência das ideias de Le Corbusier o qual dissera que o advento da civilização maquinista deveria, naturalmente, dar lugar a uma nova estética, também se referindo aos meios de transporte. Outra ideia derivada de Le Corbusier, que será explorada adiante, é de que a arquitetura se dividiria em duas partes diferentes: uma de criação individual, da paixão, e outra de cálculo, ou seja, da razão (LEONÍDIO, 2007).

Na página 24 da "versão 2", Alberto Xavier atenta para o "Desacordo entre a arte acadêmica e a técnica" (1962, p. 24). Segundo Costa, a arquitetura vigente não responderia às necessidades atuais, condizentes com seu tempo, pois estaria ligada a uma tradição, cujo embasamento estaria ultrapassado. ${ }^{24}$ Nesse sentido, o arquiteto questiona a propagação dessas ideias e da arquitetura ensinada e difundida na academia, denunciando o descompasso entre técnica e os fundamentos acadêmicos.

Ao investigar os argumentos da arquitetura acadêmica e os valores de pureza que ela buscaria preservar, Lucio Costa os descreve como sendo apenas a mera sombra da verdade, pois seriam buscados em fontes equivocadas (COSTA, 1995).

Nesse trecho, Costa compara os norte-americanos aos romanos, que copiavam os gregos em aparência e não na relação coerente entre técnica contemporânea e soluções arquitetônicas. Consideramos este, um prenúncio do pensamento de Lucio Costa sobre uma tradição legítima, pois, a maneira como a referência foi utilizada é criticada, mas não o ato de se referenciar ao passado em si. Ainda no âmbito dessa comparação, o arquiteto cita outras semeIhanças. Na "Versão 1" e na"Versão 2" utiliza: (...) o próprio jeitão dos senadores e até mesmo a mania 


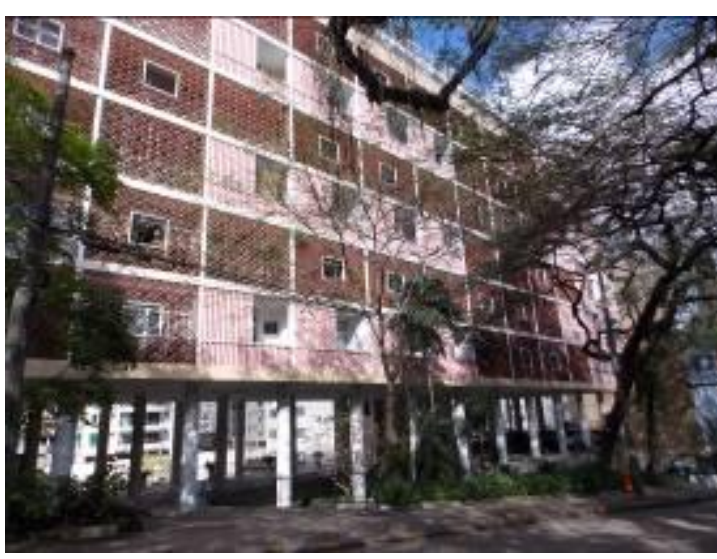

Figura 1. Foto do edifício Caledônia no Parque Guinle exemplificando as possiblidades plásticas geradas pela separação entre estrutura e vedação. Fonte: Acervo do(s) Autor(es).

25. Trecho substituído

26. Palavra substituída.

27. Trecho retirado.

28. Palavra que substitui tre-

cho da "versão 1" e na "Versão

2".

usjt • arq.urb • número 28 | maio - agosto de 2020 das recepções triunfais (...) (COSTA, 1936, s/p.) e na "versão 3", (...) a mania das recepções triunfais e até mesmo o próprio jeitão dos senadores (...) (COSTA, 1995, p. 112). A ordem delas é invertida, o que dá mais ênfase ao item final, mas não altera a essência da comparação.

Em sequência no destaque "A nova técnica: ossatura independente" (XAVIER, 1962, p. 27), o arquiteto tem em vista que a arquitetura vigente estaria em desacordo com a nova técnica, e como já visto este é o problema central do texto. Antes o caminhar evolutivo de ambos - técnica e arquitetura - e o encontro de cada lado com o outro tinha um ritmo que se devia aos processos construtivos provenientes do trabalho manual, mas com o rompimento das barreiras iniciais o equilíbrio entre os termos se deu a partir de novas diretrizes. Dessa forma, definir o funcionamento da nova técnica nesse mecanismo seria parte importante na solução da questão. Assim, Costa reivindica o papel transformador da técnica. Isso interferiria no modo de pensar os sistemas construtivos para a ossatura independente, parte fundamental dessa nova técnica. Tal revolução causada pela maior liberdade entre estrutura e vedação geraria novas possibilidades plásticas, que se configuram então como funções separadas, e a utilização de diferentes materiais como pode se observar na (Figura 1) do edifício Caledônia, projeto de Lucio Costa no Parque Guinle, 1954.
Nesse trecho, a divisão em parágrafos é igual nas "versões 1 e 2" e diferente na "versão 3". Um parágrafo de poucas linhas nas duas primeiras é incorporado ao próximo na "versão 3", em 1995, mas isso não altera seu sentido, apenas forma um parágrafo maior. Contudo, algumas palavras são substituídas e uma parte é suprimida na "versão 3", como destacado abaixo:

"Versão 1" e "Versão 2": Em todas as arquiteturas passadas, ${ }^{25}$ as paredes, de cima abaixo do edifício cada vez mais espessas até se esparramarem solidamente ancoradas ao solo, desempenharam função capital: formavam a própria estrutura, o verdadeiro suporte de toda a fábrica. Um milagre veio, porém, libertá-las dessa carga secular. A revolução, imposta pela nova técni$\underline{\mathbf{c a}^{26}}$ conferiu outra hierarquia aos elementos da construção, destituindo as paredes do pesado encargo que Ihes fora sempre atribuído. E do qual, seja dito bem a verdade, souberam desempenhar-se a contento e com inexcedível "dedicação". Embora essa destituição possa representar, sobre o ponto de vista estritamente moral, um rebaixamento necessário se torna, no entanto convir, que, em idade tão avançada e na contingência de precisar resistir a esforços sempre maiores, mantê-las no cargo, seria expor-se a surpresas desagradáveis, de consequências imprevisíveis. ${ }^{27}$ Nova função (...) (COSTA, 1936, s/p., grifos nossos).

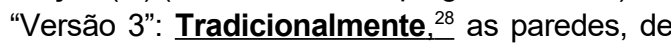
cima abaixo do edifício cada vez mais espessas até se esparramarem solidamente ancoradas ao solo, desempenharam função capital: formavam a própria estrutura, o verdadeiro suporte de toda a fábrica. Um milagre veio, porém, libertá-las 
dessa carga secular. A revolução, imposta pela nova tecnologia ${ }^{29}$ conferiu outra hierarquia aos elementos da construção, destituindo as paredes do pesado encargo que lhes fora sempre atribuído. Nova função (...) (COSTA, 1995, p. 112 , grifos nossos).

Nas mudanças apresentadas acima observamos, baseado apenas na troca de palavras do trecho, que nas primeiras versões Lucio Costa considerou como "todas as arquiteturas passadas" aquelas que "as paredes [...] cada vez mais espessas..." e depois, na reedição do texto, quando pôde se retratar dessa generalização utilizou "tradicionalmente" para se eximir de exemplificar arquiteturas do passado em que estrutura e vedação já se dissociassem. Certamente, foi menos taxativo no uso das palavras na versão de 1995, não excluindo totalmente a existência de tais arquiteturas em períodos anteriores.

Posteriormente, no texto "Documentação necessária" de 1938 (COSTA, 1962) Lucio Costa desenvolve e se aprofunda nas relações entre técnica contemporânea e tradição. Diferente de em "Razões da nova arquitetura", neste texto o arquiteto é específico sobre a tradição a ser seguida que seria a luso-brasileira. Assim, ele consegue traçar um paralelo mais preciso entre as paredes das construções coloniais e a estrutura independente.

29. Palavra substituída.

30. Trecho removido em ver-

sões posteriores.

usjt • arq.urb • número 28 | maio - agosto de 2020
Além disso, a palavra "técnica" é substituída por "tecnologia" na "versão 3" não apenas nesse tre- cho, mas em outros que o seguem. Observamos a diferença do significado em dicionário da palavra "técnica" como sendo o conjunto de procedimentos ligados a uma arte ou ciência ou a maneira própria de realizar uma tarefa (INSTITUTO ANTONIO..., 2015) e, por sua vez, o da palavra "tecnologia" como o conjunto de conhecimentos científicos, dos processos e métodos na criação e utilização de bens e serviços, ou conjunto de técnicas de um domínio particular (INSTITUTO ANTONIO..., 2015). Assim, comparando as duas definições, nota-se que "tecnologia" engloba "técnica". Se "técnica" é uma maneira de realizar uma determinada tarefa, a prática, a "tecnologia" é o conjunto delas, considerando, assim, a amplitude das novas técnicas que conformariam a nova tecnologia construtiva.

Ainda no referente à mesma temática, os seguintes trechos foram inteiramente suprimidos na "versão 3":

"Versão 1" e "Versão 2": (...) Assim, aquilo que foi invariavelmente, uma espessa muralha durante várias dezenas de séculos, pôde em algumas dezenas de ano, graças a nova técnica transformar-se (quando convenientemente orientada, bem entendido: sul no nosso caso) em uma simples lâmina de cristal. Certas pessoas se mostram alarmadas quando se fala em vidro, como se aqueles compartimentos necessários em diferentes circunstâncias, a certas atitudes igualmente indispensáveis e variadas, devessem também ser de vidro: poderão continuar fechados, ou apenas translúcidos, não há como recear, a dignidade será mantida ${ }^{30}$ 
31. Trecho removido em versões posteriores.

32. Palavra adicionada posteriormente.

33. Palavra adicionada posteri-

ormente.

34. Palavra substituída.

35. Palavra substituída.
(COSTA, 1936, s/p., grifos nossos).

"Versão 1" e "Versão 2": Parede e suporte (...) fabricadas com materiais leves, à prova de som e das variações de temperatura; livres do encargo rígido de suportar, deslizam ao lado das colunas impassíveis, param a qualquer distância, ondulam acompanhando o movimento normal do tráfego interno, permitindo outro rendimento ao volume construído; concentrando o espaço onde ele se torne necessário, reduzindo-o ao mínimo naqueles lugares onde se apresente supérfluo ${ }^{31}$ (COSTA, 1936, s/p., grifos nossos).

As alterações em relação à técnica demonstram, depois de passar por revisão em 1995, posicionamentos menos incisivos. Os trechos, que antes enfatizavam as promessas e a certeza na transformação técnica, garantindo a preservação de valores aos quais a crítica parecia receosa da perda, são retirados.

O ponto seguinte é chamado "A expressão do edifício" (XAVIER, 1962, p. 29), indicando que, depois de definida a nova técnica, se poderia definir a nova arquitetura mais condizente com ela. Assim, a nova arquitetura derivaria, sobretudo, da independência entre suporte e vedação, o que geraria novas possibilidades compositivas no jogo entre cheios e vazios, alterando a lógica dos valores da qualidade plástica. Dessa forma, Costa defendia esta arquitetura, surgida dos novos parâmetros, das críticas quanto a seu valor plástico, pois, esta teria origem conceitual diferente da arquitetura acadêmica, e, assim, tais críticas já não se aplicariam.

Destacando as alterações, vemos uma série de palavras retiradas. Como na "Versão 3": (...) o jogo de cheios e vazios. Conquanto esse contraste e confronto, ${ }^{32}$ uma das preocupações capitais de toda a arquitetura (...) (COSTA, 1995, p. 113, grifos nossos).

Nesse trecho, o uso da palavra "confronto" quando sinônimo de "contraste" pode ser apenas enfático, mas também pode adicionar uma camada de significado à frase, na medida em que, segundo definição em dicionário, o ato de confronto ou enfrentamento exige resposta, solução, não apenas o convívio de diferenças. (INSTITUTO ANTONIO..., 2015).

A seguir, mais palavras são substituídas:

"Versão 1" e "Versão 2": A nova técnica, no entanto, conferiu a esse jogo imprevista elasticidade ${ }^{33}$ permitindo à arquitetura uma intensidade de expressão até então ignorada: a linha melódica das janelas corridas, a cadência uniforme dos pequenos vãos isolados, a densidade dos espaços fechados, a leveza dos panos de vidro, tudo voluntariamente $^{34}$ excluindo qualquer ideia e esforço, que todo se concentra, em intervalos iguais, nos pilotis ${ }^{35}$ (COSTA, 1936, s/p., grifos nossos). 


\author{
36. Palavra substituída. \\ 37. Palavra substituída. \\ 38. Trecho que substitui pala- \\ vra.
}

usjt • arq.urb • número 28 | maio - agosto de 2020
"Versão 3": A nova técnica, no entanto, conferiu a esse jogo imprevista liberdade ${ }^{36}$ permitindo à arquitetura uma intensidade de expressão até então ignorada: a linha melódica das janelas corridas, a cadência uniforme dos pequenos vãos isolados, a densidade dos espaços fechados, a leveza dos panos de vidro, tudo deliberadamente $^{37}$ excluindo qualquer ideia de esforço, que todo se concentra, em intervalos iguais, nos pontos de apoio ${ }^{38}$ (COSTA, 1995, p. 113, grifos nossos).

Muitas palavras foram alteradas no trecho em que se explora as características da nova arquitetura da "versão 3", quando comparada às primeiras duas versões analisadas, , sendo elas: "elasticidade", que, quando substituída por "liberdade", pode ter significação mais abrangente e reforçar o aumento de possibilidades compositivas proporcionados pela nova técnica, sendo que "elasticidade" tem por significado ser a propriedade de um corpo sofrer deformação, quando submetido à tração, e retornar a forma original (INSTITUTO ANTONIO..., 2015) e a palavra "liberdade" possui definições mais amplas, mesmo sem mencionar suas aplicações em correntes filosóficas, sendo o direito de expressar qualquer opinião e agir como quiser; independência; licença, permissão; condição de não ser prisioneiro ou escravo; atrevimento, intimidade (INSTITUTO ANTONIO..., 2015).

"Voluntariamente" é substituída por "deliberadamente", em que o sentido de ato intencional é reforçado. Ainda que no primeiro caso seja evidente o consentimento, no segundo a intenção é melhor sinalizada. A palavra "voluntariamente" tem por definição em dicionário ser espontâneo; não ser forçado (INSTITUTO ANTONIO..., 2015). Já a palavra "deliberadamente" significa aquilo que foi decidido; resolvido; com intenção, de propósito. (INSTITUTO ANTONIO..., 2015).

A palavra "Pilotis", posteriormente, na versão de 1995, é trocada por "pontos de apoio", um termo menos específico em relação a conceitos arquitetônicos modernos utilizados pela escola carioca, ao contrário de "pilotis", sistema de colunas organizadas de forma a deixar o pavimento livre, que está fortemente ligado à arquitetura moderna e aos cinco pontos da arquitetura de Le Corbusier.

No próximo título chamado "Efeitos de materiais impróprios" (XAVIER, 1962, p. 31), Costa critica a escolha do que para ele são materiais impróprios, porque, assim, seriam desperdiçadas as vantagens da nova técnica, numa opção em que nada haveria de diferente das arquiteturas do passado.

Como pudemos ver até agora, os argumentos de Lucio Costa a favor da revisão da arquitetura vigente baseavam-se no advento da nova técnica e da ossatura independente, e, mais do que isso, no seu bom uso, aproveitando ao máximo suas possibilidades. Entretanto, apesar da existência da tecnologia do concreto, no Brasil, seu uso ainda esbarraria em outro limite: a produção industrial atrasada, proble- 
ma evidenciado em "A necessidade de interessar a indústria" (XAVIER, 1962, p. 31), trecho no qual Lucio Costa coloca que apesar de a arquitetura ser mais importante e a tecnologia apenas um ponto de partida, esta deve vir na frente abrindo caminho para que a indústria supra as necessidades do projeto.

Apesar de a nova arquitetura não atender aos mesmos critérios de avaliação sobre valores plásticos, porque seria consequência de uma nova técnica e de um novo tempo, Costa defende que ela apenas se absteria de "artificialismos" acadêmicos e que isso não queria dizer que valores como a simetria não permaneceriam; pelo contrário, a simetria significaria harmonia de composição e deveria ser respeitada pelos arquitetos.

Sobre a nova arquitetura, além dos comentários sobre a simetria, o arquiteto rebate críticas como a da uniformidade de tipos e da monotonia no trecho intitulado "Um verdadeiro estilo" (XAVIER, 1962, p. 32). Ele alegava que um "certo ar de família" que demonstra cuidado e coerência estaria presente nos grandes estilos; a diferença apenas estaria no costume de variedade, próprio da arquitetura eclética, que não fazia falta antes. Nessa mesma lógica seguida pelo arquiteto, se a arquitetura de aparência industrial, e ausente de ornamentação, é consequência direta da nova técnica, que é um sistema construtivo de aplicação geral, e seria conforme às questões daquele momento em relação à economia e ao uso, é natural que seja uniforme. E sobre a monotonia ele argumenta que, se a nova arquitetura estava sendo construída em resposta a tais questões, então faria sentido que houvesse alguma repetição (COSTA, 1995, p. 114).

Nessa parte há a substituição da palavra confusão por equívoco na passagem das versões 1 e 2 para a 3, mas, segundo definição em dicionário as duas são sinônimos. (INSTITUTO ANTONIO..., 2015), como pode ser visto a seguir:

"Versão 1" e "Versão 2": Não se trata porém, como apressadamente se concluiu, incidindo em lamentável confusão, ${ }^{39}$ de um estilo reservado, apenas, a determinada categoria de edifícios mas de um sistema construtivo absolutamente geral (COSTA, 1936, s/p., grifo nosso).

"Versão 3": Não se trata porém, como apressadamente se concluiu, incidindo em lamentável equívoco, ${ }^{40}$ de um estilo reservado, apenas, a determinada categoria de edifícios mas de um sistema construtivo absolutamente geral (COSTA, 1995, p. 114, grifo nosso).

Na sequência, quanto à aparência da nova arquitetura e à falta de ornamentação em "A ausência da ornamentação; ornato e enfeite" (XAVIER, 1962, p. 34), Lucio Costa defende que não é mero capricho e, sim, "a consequência lógica da evolução da técnica construtiva". Se a nova arquitetura responde à nova técnica e não pode ser julgada por critérios anteriores a ela, porque antes as limitações estavam ligadas ao trabalho manual, então, o enfeite e o or-
39. Alteração no texto.

usjt • arq.urb • número 28 | maio - agosto de 2020 
namento não fazem mais o mesmo sentido de antes quando se procede a industrialização.

Sobre esse tema, a única alteração é a substituição de "qualquer", palavra mais enfática quando despreza completamente o valor de documento humano do ornato por "maior", que, nesse caso apenas diminui seu valor na "versão 3", de 1995.

"Versão 1" e "Versão 2": (...) industrializou o ornato, transformando-o em artigo de série, comercial, tirando-lhe assim a principal razão de ser, a intenção artística, despindo-se de qualquer $^{41}$ interesse como documento humano (COSTA, 1936, s/p., grifo nosso).

"Versão 3": (...) industrializou o ornato, transformando-o em artigo de série, comercial, tirandoIhe assim a principal razão de ser, a intenção artística, despindo-se de maior $^{42}$ interesse como documento humano (COSTA, 1995, p. 114, grifo nosso).

Nas primeiras versões do texto - 1 e 2 -, Lucio Costa utiliza quatro parágrafos para dissertar sobre as artes, intitulando-os de "Escultura" (XAVIER, 1962, p. 35) e "Pintura" (XAVIER, 1962, p. 35). Primeiro, ele questiona a forma dos arquitetos e do público de se relacionarem com a arte e, depois, discursa sobre as particularidades da escultura e da pintura. Entretanto, todos esses parágrafos foram retirados da edição de 1995.
Contra a acusação de internacionalismo da nova arquitetura em "A internacionalização da arquitetura" (XAVIER, 1962, p. 37), Costa rebate dizendo que é uma preocupação tardia, já que existiram arquiteturas assim no passado, influenciadas e difundidas pelo poder centralizador da Igreja, por exemplo. Contudo, também não lhe dá uma origem nacional, judaica, germânica ou eslava. Ele defende a nova arquitetura como um princípio, no qual o importante é a essência, que condiz com seu tempo e sua técnica, mesmo que as formas variem, e que isso, para ele, se filie às tradições mediterrâneas, de gregos ou latinos (COSTA, 1995, p. 115).

Ainda nos argumentos finais, o texto sofre alterações das "versões 1 e 2" para a "3", falando com maior distância do período pós-guerra e das raízes do movimento moderno na Rússia e na Alemanha:

"Versão 1" e "Versão 2": Nada tem tampouco de germânica, conquanto na Alemanha mais do que em qualquer outro país, o após-guerra, juntandose às verdadeiras causas anteriormente acumuladas, ${ }^{43}$ criasse atmosfera propícia, servindo de pretexto $^{44}$ à sua definitiva eclosão. [...] Com efeito, enquanto nos países de tradição latina, inclusive as colônias americanas de Portugal e Espanha, a arquitetura barroca soube sempre manter, mesmo nos momentos de delírio a que por vezes chegou, certa compostura, até dignidade, conservando-se a linha geral da composição, conquanto elaborada, alheia ao assanhamento ornamental, nos países de raça germânica, encontrando no barbarismo atávico, recalcado pelas boas maneiras do renascimento, campo 
45. Trecho substituído.

46. Trecho substituído.

47. Trecho substituído.

48. Trecho retirado.

49. Palavra substituída.

50. Palavra substituída.

51. Palavra substituída. propício ${ }^{45}$, frutificou, atingindo a um grau de licença, senão mesmo deboche plástico, ${ }^{46}$ sem precedentes (COSTA, 1936, s/p., grifos nossos).

"Versão 1" e "Versão 2": Agora, estimulados pelo nacionalismo racista, no seu apelo aos últimos vestígios de aspereza gótica que possam, por ventura, ainda esconder sob o brilho da "kultur", é fácil reconhecer no "modernismo" alemão os traços inconfundíveis desse barroquismo, ${ }^{47}$ apesar das exceções, merecedoras de menção, entre as quais, além de Walter Gropius, a da obra verdadeiramente notável de Mies van der Rohe: milagre da simplicidade, elegância e clareza, cujos requintes, longe de prejudicá-la, dão-nos uma ideia precisa do que já hoje poderiam ser as nossas casas, não estivesse a burguesia tão entretida na consumação do próprio suicídio ${ }^{48}$ (COSTA, 1936, s/p., grifos nossos)

"Versão 3": Nada tem tampouco de germânica, conquanto na Alemanha mais do que em qualquer outro país, o após-guerra, juntando-se às verdadeiras causas anteriormente assinaladas, ${ }^{49}$ criasse atmosfera propícia, à sua definitiva eclosão. [...] Com efeito, enquanto nos países de tradição latina, inclusive as colônias americanas de Portugal e Espanha, a arquitetura barroca soube sempre mante, mesmo nos momentos de delírio a que por vezes chegou, certa compostura, até dignidade, conservandose a linha geral da composição, conquanto elaborada, alheia ao assanhamento ornamental, nos países de raça germânica, encontrando campo apropriado, ${ }^{50}$ frutificou, atingindo mesmo, em alguns casos, a um grau de licenciosidade $^{51}$ sem precedentes (COSTA, 1995, p. 115 , grifos nossos)
"Versão 3":Ainda agora é fácil reconhecer no modernismo alemão os traços inconfundíveis desse barroquismo, apesar das exceções, merecedoras de menção, entre as quais, além de Walter Gropius, a da obra verdadeiramente notável de Mies van der Rohe: milagre da simplicidade, elegância e clareza, cujos requintes, longe de prejudicá-la, dão-nos uma ideia precisa do que já hoje poderiam ser as nossas casas (COSTA, 1995, p. 115, grifos nossos)

Segundo definição em dicionário, a palavra "acumula", que foi substituída por "assinalado", significa reunir ordenada ou desordenadamente, amontoar, empilhar; realizar sucessivamente; exercer (cargos, funções) simultaneamente; juntar, poupar. Já "assinalado", por sua vez, significa marcado com sinal; indicado, apontado; ilustre (INSTITUTO ANTONIO..., 2015). Portanto, as causas da eclosão da nova arquitetura se relacionam, de forma que, se ao utilizar o termo "acumuladas" essas razões servem apenas como pretexto, com o uso da palavra a palavra "assinaladas", por outro lado, demonstra que tais razões já existiam e que Lucio Costa apenas as enuncia, as indica.

Já outros trechos retirados demonstram certa agressividade no uso de alguns termos como "barbarismo" ou "deboche", citados anteriormente, assim como, quando Costa explica o porquê das casas de seu tempo ainda não se assemelharem à obra como a de Mies van der Rohe, e culpa a burguesia que no seu ponto de vista se encontraria entretida no próprio suicídio (COSTA, 1936). 
52. Palavra substituída.

53. Palavra substituída.

54. Palavra substituída.

55. Palavra substituída.

56. Lucio Costa estudou a obra de Le Corbusier em "chômage", de 1932 a 1935, anteri-

or à publicação do texto em

1936 (COSTA, 1995 p. 27,

135).

usjt • arq.urb • número 28 | maio - agosto de 2020
Por fim, Lucio Costa termina sua argumentação falando sobre a relação dos russos com as raízes da nova arquitetura, na qual as aparências indicariam a aproximação do resultado esperado por ele, como as experiências iniciais com o construtivismo, no campo da arte, e termina seu discurso classificando a arquitetura russa como nova e não boa como anteriormente redigido, ou seja, sem um juízo de valor.

"Versão 1" e "Versão 2": (...) Para comprová-lo, basta que se note a maneira pouco feliz com que os russos, apesar de certas aparências, ${ }^{52}$ dela se tem servido, e que atesta uma estranha incompreensão. Torna-se, mesmo, curioso observar que a Rússia, como as demais nações, também reage, presentemente, contra os princípios da $\underline{\text { boa }^{53}}$ arquitetura (...) (COSTA, 1936, $\mathrm{s} / \mathrm{p} .$, grifos nossos).

"Versão 3": (...) Para comprová-lo, basta que se note a maneira pouco feliz com que os russos, apesar de certas experiências iniciais com o construtivismo, ${ }^{54}$ dela se tem servido, e que atesta uma estranha incompreensão. Torna-se, mesmo, curioso observar que a Rússia, como as demais nações, também reage, presentemente, contra os princípios da nova ${ }^{55}$ arquitetura (...) (COSTA, 1995, p. 115, grifos nossos).

\section{Considerações finais}

Ao levarmos em conta as comparações apresentadas neste artigo, consideramos antes de tudo que o fato de a premissa inicial do texto ser a imprecisão presente em uma fase de transição reflete o período em que a primeira versão foi publicada. Nesse contexto, se vivenciava mudanças significativas no campo da arquitetura, como o surgimento de novas possibilidades técnicas, e Lucio Costa analisa as origens do que para ele é um descompasso entre a técnica e a arquitetura produzida. $\mathrm{O}$ autor baseado nelas, escreve um texto propositivo, defendendo a reformulação da arquitetura vigente segundo novos princípios mais coerentes com seu tempo, influenciados pela obra escrita de Le Corbusier. ${ }^{56}$

Dessa forma, Costa conclui o texto propondo que uma nova ordem, depois de conquistada e passada toda a turbulência, seria natural e até difícil de aceitar que algum dia houvera qualquer recusa inicial, como mostra a citação a seguir.

$E$ aqueles que, num futuro talvez não tão remoto como o nosso comodismo de privilegiados deseja, tiveram a ventura, ou o tédio, de viver dentro da nova ordem conquistada, estranharão, por certo, que se tenha pretendido opor criações de origem idêntica e negar valor plástico a tão claras afirmações de uma verdade comum (COSTA, 1995, p. 115).

A certeza em uma nova ordem que viria naturalmente, assim como certa rispidez de termos na primeira versão em 1936, bem como na segunda versão, e que é amenizada na versão de 1995, mostram um posicionamento firme frente ao que ele 
próprio chama na introdução do texto, em seu livro Registro de uma vivência, de "guerra santa profissional" (COSTA, 1995, p. 108).

A nova técnica também é elemento-chave na construção do texto, já que o arquiteto afirma que seu surgimento e a necessidade de a acompanhar seriam os maiores causadores do descompasso para o qual ele busca solução na produção de uma nova arquitetura. Assim, a maior quantidade de alterações observada contempla, sobretudo, a temática da nova técnica, bem como, a a da nova arquitetura.

Essas definições são construídas no texto pelo próprio autor tendo em vista que a ossatura independente é eleita como integrante de princípios de coerência com a a nova técnica, porque traria em seu bojo a possibilidade de novas liberdades compositivas, e teria como consequência a nova arquitetura. Esta é definida pelo arquiteto a partir de respostas às premissas e aos problemas centrais decorrentes da instabilidade, em um período de transição, e percepção de um desacordo da arquitetura vigente produzida no Brasil. Essa nova arquitetura é defendida por Costa das críticas, que pautado pelo desenvolvimento da técnica diz que as antigas arquiteturas se baseavam no trabalho manual e já não seriam válidas.
Algumas vezes, entretanto, na versão de 1995, Lucio Costa retira trechos ou os modifica quando fala sobre a técnica. Observamos que esta não parou de se desenvolver desde a primeira versão do texto, passados quase 60 anos, assim como as ideias do autor sobre arquitetura provavelmente sofreram mudanças, advindas das críticas sobre a arquitetura moderna, ocorridas desde o período após a Segunda Guerra.

A substituição da palavra 'pilotis' por pontos de apoio', bem como o trecho retirado em que Costa exaltava a ossatura independente, em relação as paredes autoportantes, tornam o sentido do texto menos restrito. Afinal, como visto no projeto da vila em Monlevade de 1934, alvenarias autoportantes podem ser um elemento primordial e não invalidariam a classificação do exemplar como moderno. Aliás, isto não é de se estranhar diante de processos de mudanças do contexto social, tecnológico, e, especialmente, do campo da arquitetura, em que as certezas anteriores são colocadas em escrutínio.

Em "Razões da nova arquitetura" está o princípio das ideias de Lucio Costa sobre tradição. Ele se preocupa com os avanços tecnológicos e industriais, mas não se restringe a eles e procura na tradição, dita mediterrânea nessa etapa (COSTA, 1936), respostas condizentes com seu tempo. "Razões da nova arquitetura" é apenas o princípio de uma lógica que se expande em outros textos. ${ }^{57}$ 


\section{Referências}

AMORA, Ana M. G. Albano. O Nacional e o Moderno: a arquitetura da saúde no Estado Novo nas cidades catarinenses. 2006. $340 \mathrm{f}$. Tese (Doutorado em Planejamento Urbano e Regional) - Instituto de Pesquisa e Planejamento Urbano Regional, Universidade Federal do Rio de Janeiro, Rio de Janeiro, 2006.

Arquitetura em Revista: o moderno e a tradição em dois periódicos representativos dos campos acadêmico e profissional da arquitetura e do urbanismo. In: SEMINÁRIO DOCOMOMO BRASIL, 8., 2009, Rio de Janeiro. Artigos [...]. Rio de Janeiro: Docomomo Rio, 2009. p. 1-18.

ANDRADE, Mário de. Brazil Builds. In: XAVIER, Alberto (Org.). Depoimento de uma geração - arquitetura moderna brasileira. Ed. rev. e ampl. São Paulo: Cosac \& Naify, 2003. p. 177-181.

CENTRO DE PESQUISA E DOCUMENTAÇÃO DE HISTÓRIA CONTEMPORÂNEA DO BRASIL. O governo de Juscelino Kubitschek: Universidade do Distrito Federal. Rio de Janeiro, [2017]. Fundação Getúlio Vargas (CPOC - FGV). Disponível em: $\quad$ <ttps://cpdoc.fgv.br/producao/dossies/JK/ glossario/universidade_do_distrito_federal>. Acesso em: 30 mar. 2019.
COSTA, Lucio. Razões da nova arquitetura. Revista da Diretoria de Engenharia, Brasília, DF, v. III, n. 1, jan. 1936. Disponível em: <http://www.rio.rj.gov.br/dlstatic/10112/7689530/4212159/N.3numero11936.pdf>. Acesso em: 19 dez. 2018.

COSTA, Lucio. Documentação necessária. In: . Lucio Costa: sobre a Arquitetura. Organizado por Alberto Xavier. Porto Alegre: Centro dos estudantes universitários de arquitetura, 1962. v. I.

COSTA, Lucio. Razões da nova arquitetura. In: . Lucio Costa: sobre a Arquitetura. Organizado por Alberto Xavier. Porto Alegre: Centro dos estudantes universitários de arquitetura, 1962. v. I.

COSTA, Lucio. Razões da nova arquitetura. In: Lucio Costa: registro de uma vivência.

São Paulo: Empresa das Artes, 1995.

GRAEFF, Edgar. Nota introdutória. In: Lucio Costa: sobre a Arquitetura. Organizado por Alberto Xavier. Porto Alegre: Centro dos estudantes universitários de arquitetura, 1962. v. I.

INSTITUTO ANTONIO HOUAISS DE LEXICOGRAFIA. Houaiss: pequeno dicionário Houaiss da língua portuguesa. São Paulo: Moderna, 2015. 
NOBRE, Ana Luiza. A Razão e as razões de Lucio Costa. Revista aU, São Paulo, v. 100, fev. 2002. Edição 100. Disponível em: <http://au17.pini.com.br/arquitetura-urbanismo/100/a-razao-e-as-razoesde-lucio-costa-23781-1.aspx>. Acesso em: 19 dez. 18.

RIBEIRO, Otavio Leonídio. Carradas de razões: Lucio Costa e a arquitetura moderna brasileira (1924-1951). São Paulo: Edições Loyola, 2007. 